\title{
MUDANÇAS PALEO-HIDROLÓGICAS NA PLANÍCIE DO RIO PARAGUAI, QUATERNÁRIO DO PANTANAL
}

\section{LATE QUATERNARY PALEOHYDROLOGICAL CHANGES IN THE PARAGUAY FLUVIAL PLAIN, BRAZILIAN PANTANAL WETLAND}

Hudson de Azevedo Macedo

Instituto de Geociências e Ciências Exatas, Universidade Estadual Paulista - UNESP Av. 24A, 151, Bela VistaCEP: 13506-900, Rio Claro - SP, Brasil.

E-mail: hud_azevedo@hotmail.com

Mario Luis Assine

Instituto de Geociências e Ciências Exatas, Universidade Estadual Paulista - UNESP Av. 24A, 151, Bela VistaCEP: 13506-900, Rio Claro - SP, Brasil.

E-mail: assine@rc.unesp.br

Aguinaldo Silva

Departamento de Ciências do Ambiente, Universidade Federal de Mato Grosso do Sul - UFMS Av. Rio Branco, 1270, Bairro Universitário CEP: 79304-020, Corumbá - MS, Brasil.

E-mail aguinald_silva@yahoo.com.br

Fabiano do Nascimento Pupim

Instituto de Geociências e Ciências Exatas, Universidade Estadual Paulista - UNESP Av. 24A, 151, Bela VistaCEP: 13506-900, Rio Claro - SP, Brasil.

E-mail: fabianopupim@hotmail.com

Eder Renato Merino

Instituto de Geociências e Ciências Exatas, Universidade Estadual Paulista - UNESP Av. 24A, 151, Bela VistaCEP: 13506-900, Rio Claro - SP, Brasil.

E-mail: ermerino82@yahoo.com.br

José Cândido Stevaux

Instituto de Geociências e Ciências Exatas, Universidade Estadual Paulista - UNESP Av. 24A, 151, Bela VistaCEP: 13506-900, Rio Claro - SP, Brasil. E-mail: josecstevaux@gmail.com 


\section{Informações sobre o Artigo}

Data de Recebimento:

18/06/2013

Data de Aprovação:

01/10/2013

\section{Palavras-chave:}

Pantanal, rio Paraguai, estilos

fluviais, mudanças paleo-

hidrológicas.

\section{Keywords:}

Pantanal wetland, Paraguay

River, fluvial patterns,

paleohydrological changes.

\section{Resumo}

O Paraguai é o rio-tronco do trato de sistemas deposicionais do Pantanal. Com base em dados de sensores remotos e verificação de campo, foi realizado mapeamento geomorfológico da planície do rio Paraguai no trecho entre as confluências dos rios Cuiabá e Miranda, onde foram reconhecidas formas deposicionais atuais e antigas. A análise das associações de formas permitiu estabelecer proposta de evolução geomorfológica para a área, mas os eventos carecem ainda de datação precisa por métodos geocronológicos. Uma rede de drenagem abandonada multicanais está parcialmente preservada na planície, sendo composta por formas de canais com diques marginais que evidenciam período de menor descarga fluvial, provavelmente do Pleistoceno tardio ao Holoceno inferior. Um sistema constituído por paleocinturões de meandros trunca a paleorrede de drenagem multicanais, registrando aumento na umidade e na descarga fluvial. Sob essas condições o rio Paraguai construiu um sistema composto por cinturões de meandros com direção aproximada norte-sul no Holoceno inferior/médio. Agradação dos cinturões favoreceu importante evento de avulsão, com a mudança do curso do rio Paraguai para o cinturão de meandros atual no Holoceno superior. As gerações de formas identificadas e mapeadas resultaram num padrão de sobreposição de diferentes estilos fluviais, que registram significativas mudanças hidrológicas na planície desde o Pleistoceno tardio.

\section{Abstract}

The Paraguay River is the trunk-tributary river of the Pantanal alluvial system tract. Based on remote sensing with field data validation, a geomorphological mapping was accomplished for the Paraguay floodplain in the area comprising Cuiabá and Miranda confluences, where active and abandoned fluvial landforms were recognized. Despite that the absolute dating based on sediment data is not available, three distinct geomorphic depositional associations were mapped, which allowed us to establish the succession of the sedimentologic events occurred in late Quaternary. The oldest association is an abandoned drainage network made up of anabranching elevated ridges of channel and levees, probably formed during a period of lower river discharge from the late Pleistocene to the early Holocene. A set of north-south paleomeander belts truncate the channel-levee ridges, recording an increase of humidity and river discharge from the lower to the middle Holocene. Channel aggradation triggered an important avulsion event around the middle-late Holocene transition, causing the main channel of the Paraguay River to shift to its present-day meandering belt. The successive fluvial styles record paleohydrological changes in the Paraguay River plain since the late Pleistocene.

\section{Introdução}

O estudo da dinâmica de grandes rios é de grande interesse tanto para a geomorfologia como para a hidráulica fluvial, além de dar suporte em vários problemas concernentes às ciências ambientais que envolvem o gerenciamento e o manejo dos recursos hídricos. Neste contexto, melhor compreensão da geomorfologia fluvial do rio Paraguai é de relevância científica, uma vez que o rio Paraguai é o principal afluente do rio Paraná e integra a hidrovia Paraná-Paraguai, importante via de transporte de escoamento da produção do Centro-Oeste do Brasil.
Fluindo de norte para sul na bacia do alto Paraguai (BAP), o rio percorre 1.693 km em território brasileiro, desde suas nascentes no planalto dos Parecis até a foz do rio Apa, na divisa com o Paraguai (Figura 1). Em seu percurso, o rio atravessa as terras sazonalmente alagáveis do Pantanal, uma das principais wetlands do planeta (JUNK et al, 2006). As altitudes do Pantanal variam entre 80 e $190 \mathrm{~m}$ acima do nível do mar, caracterizando região deprimida circundada pelos planaltos de Maracaju-Campo Grande e Taquari-Itiquira a leste, Guimarães e Parecis a norte, Urucum-Amolar a oeste e Bodoquena a sul (ASSINE, 2003). 


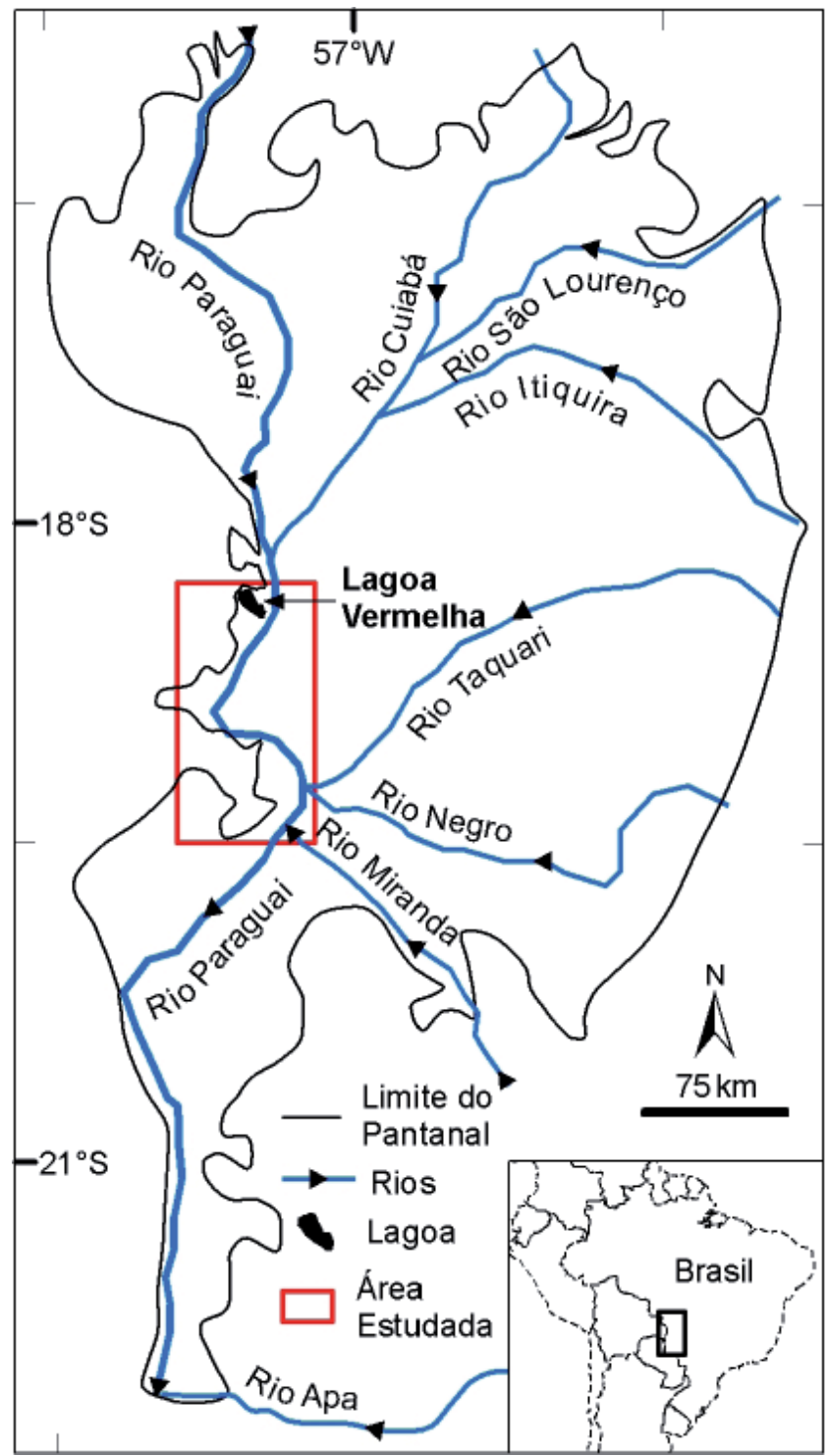

Figura 1 - Localização da área estudada.

Para compreender a geomorfologia da planície do rio Paraguai é necessário considerar que o Pantanal é uma bacia sedimentar ativa, que está sendo preenchida por um trato deposicional dominado por sedimentação aluvial, onde o rio Paraguai é o rio-tronco coletor das águas de vários megaleques (ASSINE, 2003), sendo o do rio Taquari o maior deles (ASSINE, 2005; ASSI$\mathrm{NE}$ et al., 2005). Muitas das feições geomorfológicas do Pantanal são formas relictas (TRICART, 1982; AB'SABER, 1988; SOARES et al., 2003; ASSINE; SOARES, 2004), testemunhando evolução paleogeográfica condicionada por mudanças ambientais, incluindo variações do nível de base, da precipitação e da descarga fluvial, que vêm ocorrendo na área desde o Pleistoceno tardio (ASSINE, 2003; ASSINE, 2010).

Situado na margem oeste da bacia do Pantanal, o rio Paraguai apresenta significativas mudanças no estilo de seu canal e na conformação de sua planície de inundação. A maior parte dos estudos sobre sua geomorfologia teve como foco a porção norte da planície, no trecho entre Cáceres e a ilha de Taiamã (SOUZA, 2004; SILVA et al., 2007; 2008; ASSINE; SILVA, 2009; SILVA, 2010; GRIZIO et al., 2011). No trecho a jusante da foz do rio Miranda, a caracterização da planície permitiu verificar que o rio Paraguai mudou de curso no Holoceno, com o abandono do cinturão de meandros onde se instalou o atual rio Nabileque (KUERTEN; ASSINE, 2011; KUERTEN et al., 2013).

Considerando a carência de conhecimento sobre a geomorfologia fluvial do rio Paraguai entre as confluências dos rios Cuiabá e Miranda, este artigo tem por objetivo a caracterização geomorfológica deste trecho do rio, com ênfase em evidências morfológicas de mudanças paleo-hidrológicas ocorridas na área desde o final do Pleistoceno.

\section{Materiais e Métodos}

A morfologia e o funcionamento de uma planície fluvial não são apenas produto das condições hidrodinâmicas e hidrossedimentares atuais, mas sim, fruto de um processo evolutivo no qual antigas morfologias, mesmo abandonadas, ainda interferem na dinâmica atual. Tal funcionamento, típico dos sistemas fluviais, levou Leopold et al. (1964) a afirmar que "um rio antes de uma origem tem uma herança”. Partindo dessa premissa, os estudos deste trabalho foram dirigidos de modo a, não apenas caracterizar morfologicamente a planície do rio Paraguai, mas, tentar entender sua evolução geomorfológica no contexto das mudanças climáticas ocorridas no Quaternário.

A análise geomorfológica da planície do rio Paraguai foi realizada com base em dados de sensores remotos, sobretudo imagens Landsat7 ETM+, obtidas do United States Geological Survey (USGS). As imagens óticas do sensor ETM+ foram realçadas com o uso de transformação de contraste linear, observando-se os limites do histograma para evitar a ocorrência de overflow, que representa a inclinação exagerada da reta de transferência fazendo com que a imagem contrastada exceda os limites, acarretando perda de informação (CRÓSTA, 1992).

Dados altimétricos do Shuttle Radar Topography Mission (SRTM), com resolução espacial de 90 m, 
foram utilizados na elaboração de modelos digitais de elevação (MDE’s). Ajustes nos intervalos dos MDE's produziram ganho qualitativo na imagem, permitindo a diferenciação de feições de baixa amplitude topográfica. As formas presentes na planície só foram destacadas em intervalos altimétricos com classes de um metro.

Após o processamento dos dados orbitais, os produtos (composições coloridas e MDE's) foram analisados para identificação e mapeamento das formas deposicionais existentes na planície. Os limites entre as planícies aluviais e relevos erosivos elevados foram definidos pelas diferenças altimétricas visualizadas no MDE e pelas diferenças de textura reconhecidas nas

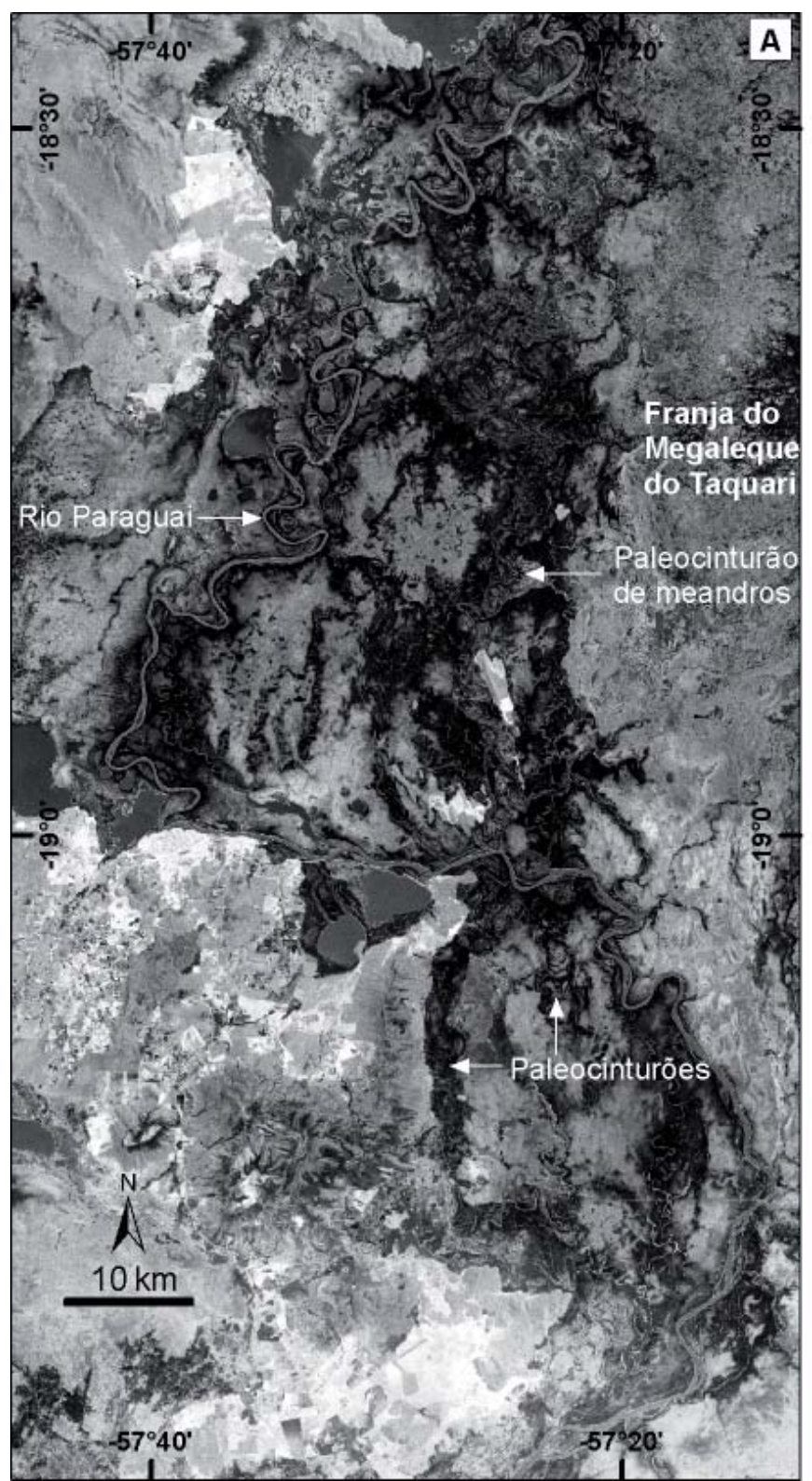

imagens ETM+. As associações de formas deposicionais da planície foram delimitadas com base em zonas homólogas definidas nas imagens óticas (composição RGB e banda 3) e pela diferença altimétrica reconhecida no MDE. Trabalhos de campo foram realizados para a validação das interpretações e caracterização das unidades mapeadas.

\section{Resultados}

A planície do rio Paraguai na área estudada foi definida pelo reconhecimento de formas de terreno que tem relação genética com o rio Paraguai (atual e pretérito).

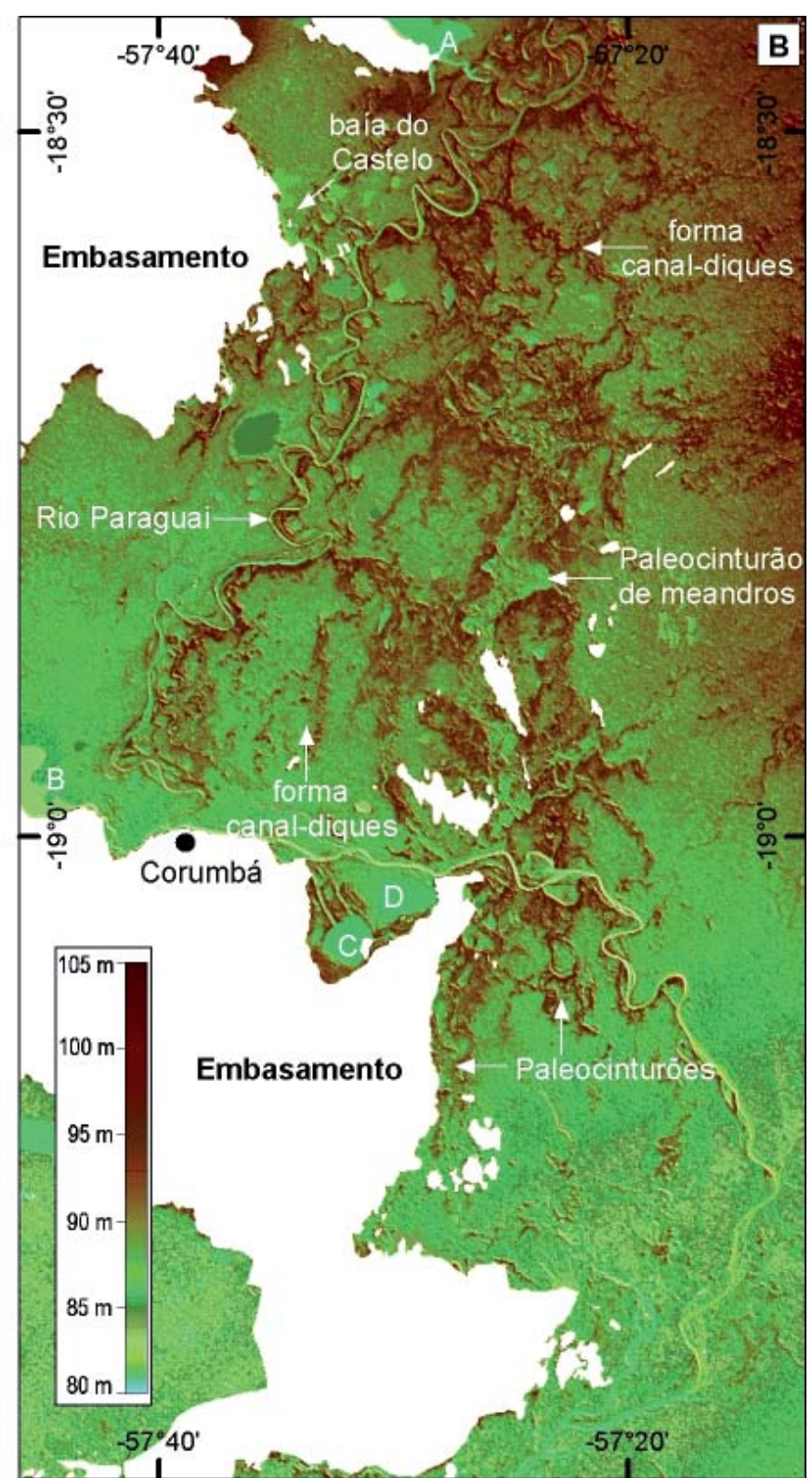

Figura 2 - Paleocinturões de meandros e formas canal-diques na planície de inundação. A) imagem Landsat 7 ETM+, banda 3 (setembro de 1999); B) modelo digital de elevação (MDE). Lagoas: $A=$ Vermelha; $B=$ Cáceres; $C=$ Negra; $D=$ Arroz. 


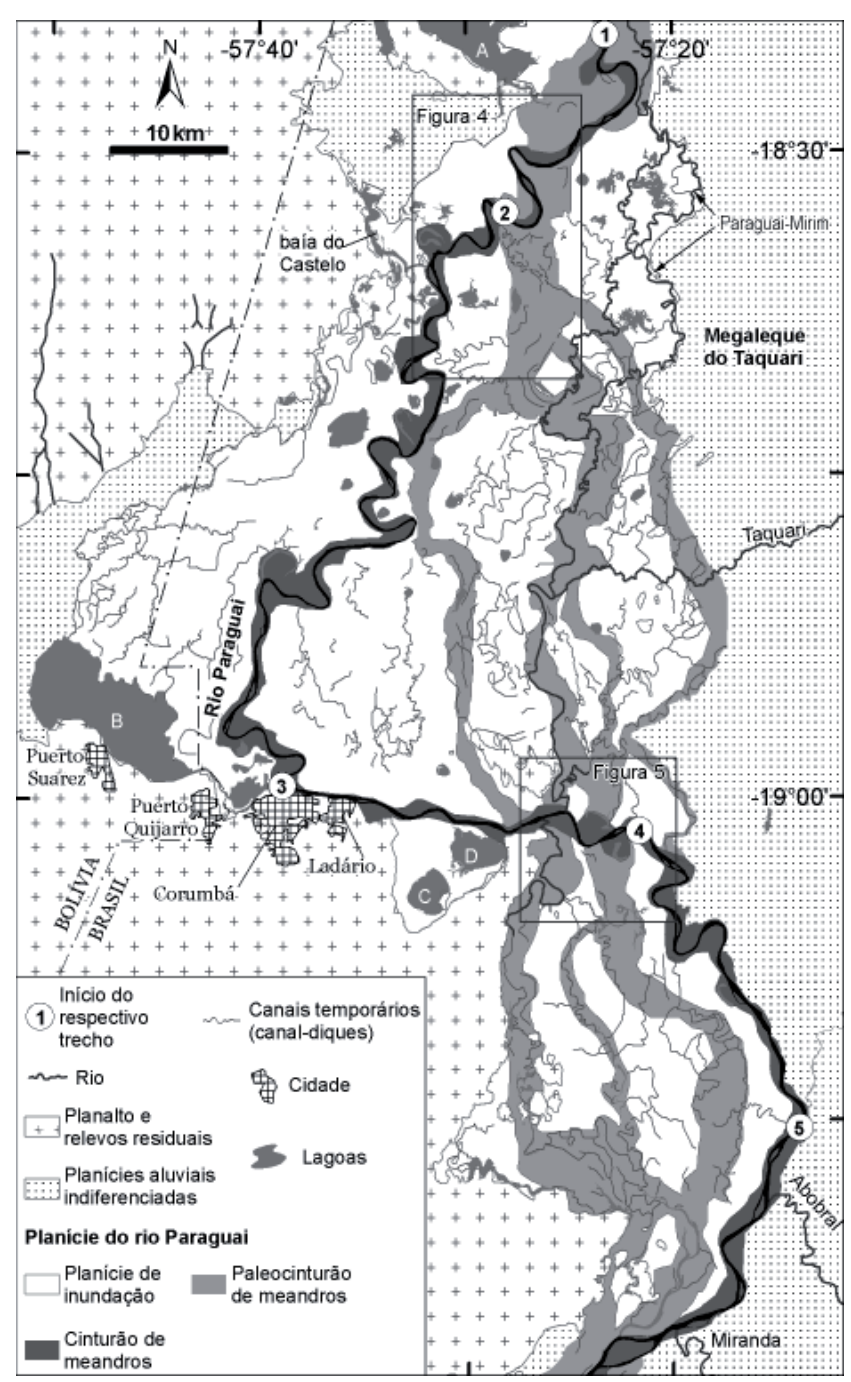

Figura 3 - Associações de formas deposicionais na planície do rio Paraguai: a) planície de inundação; b) paleocinturões de meandros; c) cinturão de meandros. O início dos trechos em que foi compartimentado o cinturão de meandros é indicado pelos números 1 a 5. (Lagoas: $A=$ Vermelha; $B=$ Cáceres; $C=$ Negra; $D=$ Arroz).

Seu limite oeste é definido principalmente pelos relevos mais elevados, sustentados por rochas cristalinas pré-cambrianas, do Planalto Residual do Urucum-Amolar e da Depressão do Rio Paraguai. Na borda leste, a planície é limitada por depósitos aluviais da franja do megaleque do rio Taquari e das planícies dos rios Negro, Abobral e Miranda, todos tributários do rio Paraguai (Figura 2).

A topografia da planície é plana e de baixa declividade, com altitudes que variam de $105 \mathrm{~m}$ na altura da lagoa Vermelha (norte) a 80 m na confluência do rio Miranda (sul). Morros isolados ocorrem no interior da planície e representam afloramentos de rochas cristalinas.
A identificação e o mapeamento de formas deposicionais geneticamente relacionadas ao rio Paraguai permitiram a compartimentação da planície fluvial em três diferentes associações morfológicas, discutidas a seguir: a) planície de inundação; b) paleocinturões de meandros; c) cinturão de meandros (Figura 3).

\section{Planície de inundação}

A planície é marcada pela presença de paleocanais estreitos com diques marginais, reconhecíveis em imagens de satélite e em MDE's como formas suavemente mais elevadas que seu entorno (Figura 2). Os paleocanais, individualizados na planície pela preservação dos seus diques marginais com vegetação arbórea, se mantêm parcialmente ativos durante as inundações. A reconstituição da paleorrede de drenagem foi dificultada pelo fato de que estes paleocanais estão em processo de obliteração pelas águas das inundações e parcialmente truncados por canais mais jovens, mas ainda assim foi possível verificar que os canais apresentavam padrão complexo com bifurcações e reunificações.

As características da planície de inundação favorecem o acúmulo de água durante a estação das chuvas. A inundação ocorre mesmo que não haja o transbordamento das águas da calha do rio Paraguai, como decorrência do acúmulo de água pluvial e da subida do nível freático, o que promove a expansão da superfície dos inúmeros pequenos lagos existente na planície. Além disto, a planície recebe águas de inundações provenientes de leste, principalmente derivadas do megaleque do Taquari.

Cursos d'água perenes marcam a planície de inundação, drenando as águas das cheias. O mais importante é o rio Paraguai-Mirim, que tem seu início num ponto de rompimento (crevasse) na margem esquerda do rio Paraguai na altura da lagoa Vermelha; cruza a planície de inundação de norte a sul e tem confluência no próprio rio Paraguai a jusante da cidade de Corumbá. Destaca-se o fato de que o Paraguai-Mirim passou a receber as águas provenientes do rio Taquari depois da avulsão Zé da Costa na década de 1990 (ASSINE, 2005; ASSINE et al., 2005).

\section{Paleocinturões de meandros}

Paleocinturões de meandros foram reconhecidos na planície do rio Paraguai, sendo compostos por paleocanais, lagoas e espiras de meandro (scroll bars), que 

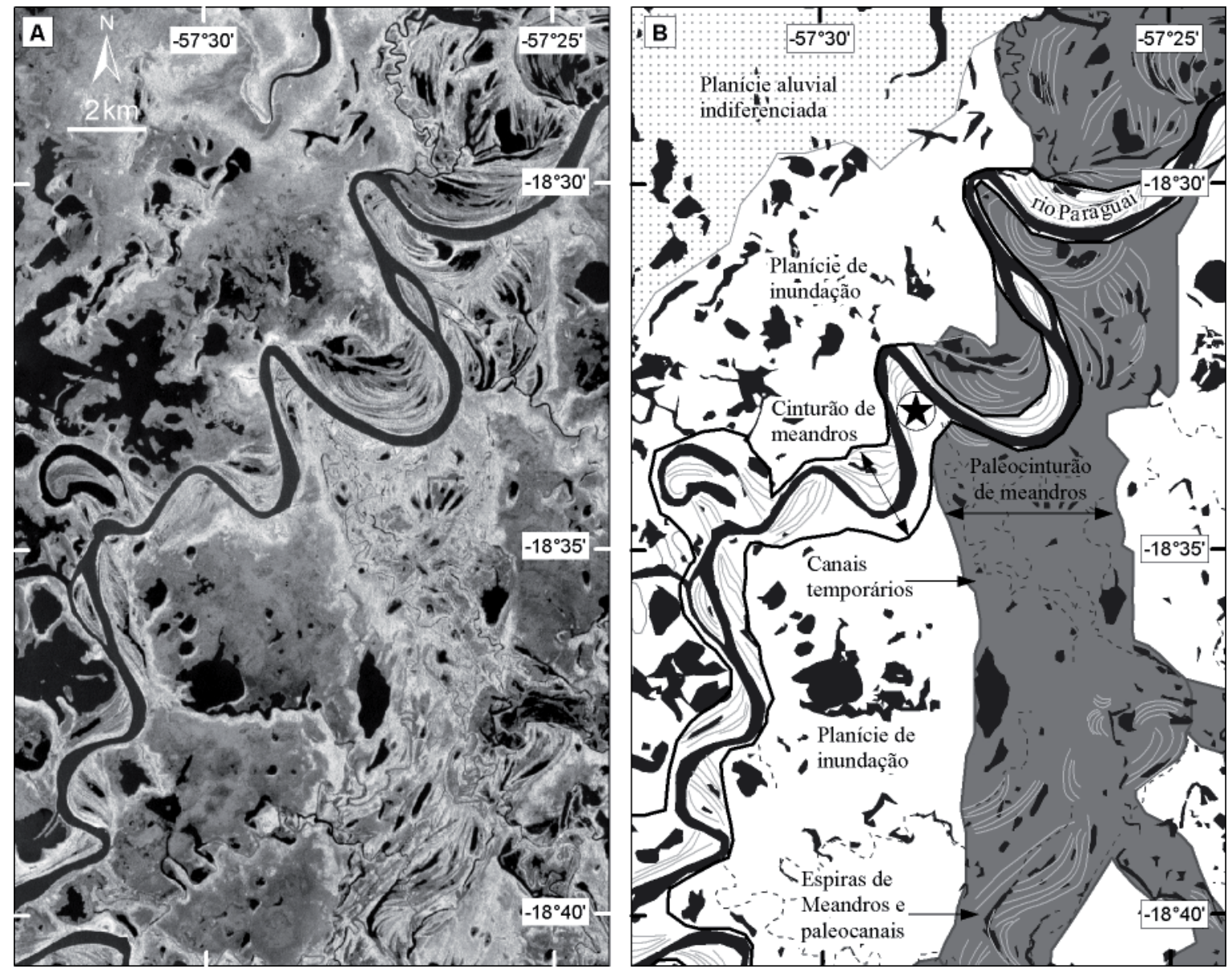

Figura 4 - Avulsão do rio Paraguai que mudou o curso para SSW em direção à lagoa Cáceres: A) imagem Landsat 7 banda 8; B) interpretação geomorfológica com indicação da localização da avulsão (indicada por símbolo de estrela).

truncam formas deposicionais mais antigas existentes na planície de inundação. Três paleocinturões foram individualizados, todos com direção aproximada NS, que se bifurcam e contornam relevos residuais de rochas pré-cambrianas existentes na área (Figura 3). Os paleocinturões possuem largura variável de 2 a $4 \mathrm{~km}$ e ficam inundados durante períodos de cheia, sendo a drenagem desta associação morfológica realizada por fluxo hortoniano e por pequenos rios temporários, localmente conhecidos pela designação de "corixos", que aproveitam paleocanais existentes nos paleocinturões.

A avulsão do rio Paraguai identificada na parte norte da área, na altura da baía do Castelo (lat. 18³4'S), é o registro mais significativo de mudança paleo-hidrológica constatada na área (Figura 4). Este evento ocasionou o abandono do paleocinturão de meandros e a mudança do curso do rio Paraguai para SSW em direção à lagoa Cáceres.

\section{Cinturão de meandros}

O cinturão de meandros está encaixado na planície, truncando formas deposicionais da planície de inundação e dos paleocinturões de meandros. É composto por diversas formas deposicionais, tais como o canal atual do rio Paraguai, lagoas (oxbow lakes), barras em pontal (point bars), diques marginais e ilhas. Foi subdividido em cinco trechos com base nas características morfológicas e sinuosidade do rio Paraguai (Tabela 1).

$\mathrm{O}$ rio corre no rumo SSW nos dois primeiros trechos, desde a lagoa Vermelha até a lagoa Cáceres. A largura do cinturão de meandros e a sinuosidade do canal aumentam do primeiro para o segundo trecho, cujo limite foi posicionado nas proximidades da baía do Castelo (Figura 3). O limite coincide com o local onde o rio abandonou os paleocinturões de meandros e passou a correr no cinturão de meandros, na importante avulsão referida anteriormente (Figura 4). 

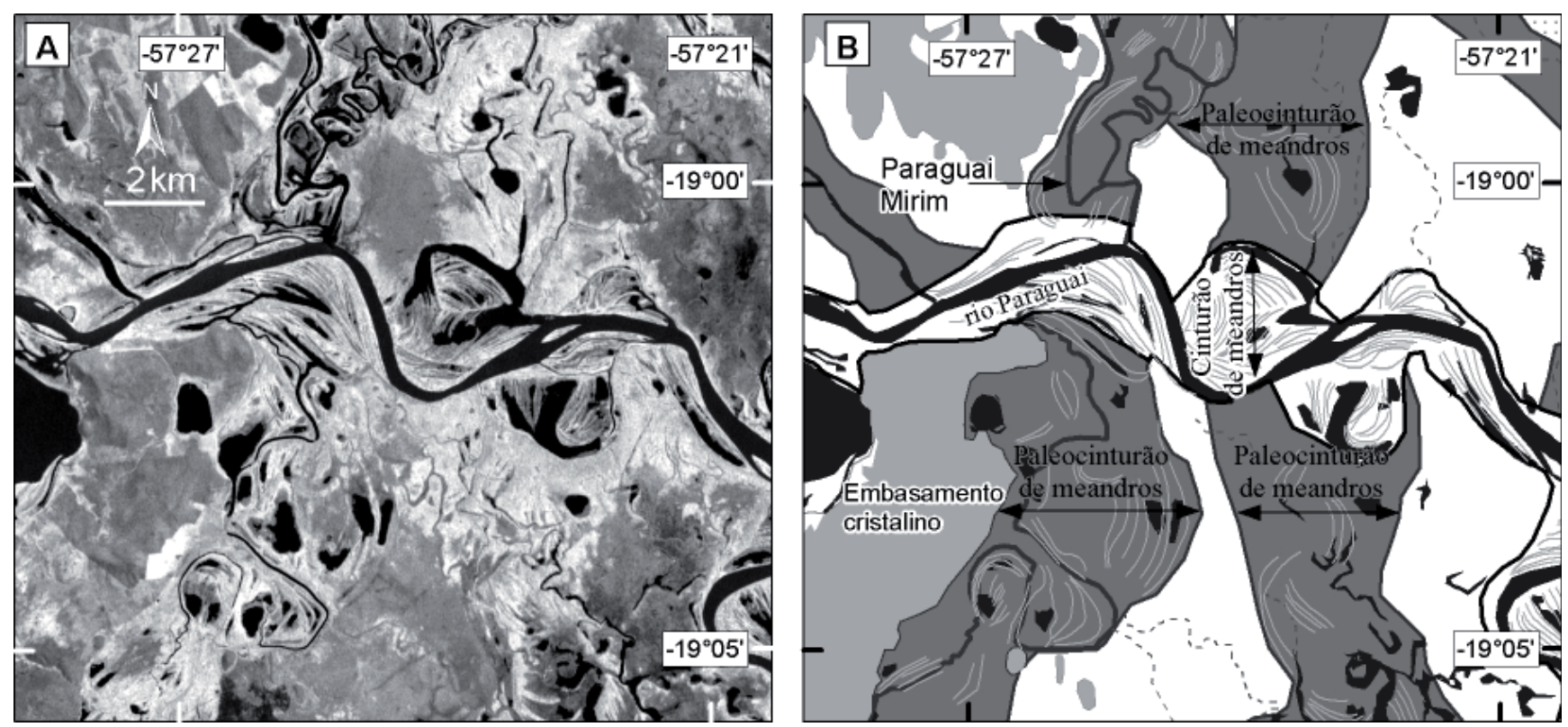

Figura 5 - Paleocinturão de meandros cortado pelo cinturão de meandros, na confluência do rio Paraguai-Mirim. A) imagem Landsat 7 banda 8; B) interpretação geomorfológica.

Tabela 1 - Parâmetros morfométricos para cada trecho do cinturão de meandros do rio Paraguai.

\begin{tabular}{cccc}
\hline Trecho & $\begin{array}{c}\text { Sinuosidade } \\
\text { do canal }\end{array}$ & $\begin{array}{c}\text { Largura } \\
\text { média do } \\
\text { cinturão }(\mathbf{k m})\end{array}$ & Direção \\
\hline 1 & 1,62 & 1,18 & SSW \\
2 & 1,78 & 1,82 & SSW \\
3 & 1,29 & 1,29 & ESE \\
4 & 1,38 & 1,49 & SSE \\
5 & 1,19 & 1,61 & SSW \\
\hline
\end{tabular}

O canal deflete bruscamente para leste na confluência do canal do Tamengo, que liga o rio à lagoa Cáceres, configurando o terceiro trecho, cuja direção WNW é tectonicamente controlada (ASSINE; SOARES, 2004). A confluência do rio Paraguai-Mirim está situada neste trecho em que o cinturão de meandros corta os paleocinturões de direção NS (Figura 5). Mudança para SE dá início ao quarto trecho, que possui diques marginais bem desenvolvidos e pouca migração lateral do canal. Deflexão para SSW na altura do Porto da Manga marca o início do quinto e último trecho, no qual o rio corre novamente dentro do paleocinturão de meandros.

\section{Discussão dos resultados}

A literatura geomorfológica está repleta de trabalhos que citam mudanças climáticas como um dos principais fatores de alteração nas características flu- viais (KNIGHTON, 1984; MIALL, 1996; SMITH, 1996; CARAGNANO, 1999; SHUKLA et al., 2001; SOHN et al., 2007). No caso dos atuais sistemas fluviais brasileiros, a história evolutiva é influenciada pelas flutuações climáticas ocorridas principalmente a partir do Último Máximo Glacial. Tal situação foi constatada no rio Paraná (STEVAUX, 1994; 2000), do qual o Paraguai é o principal afluente. Na bacia do Pantanal, em especial, os estilos fluviais são fortemente controlados por mudanças climáticas ocorridas desde o final do Pleistoceno (ASSINE, SOARES 2004; ASSINE et al., 2014).

Mudanças paleoambientais foram reconhecidas na planície do rio Paraguai, tanto a norte, no trecho entre Cáceres e a confluência do rio Cuiabá (ASSINE; SILVA, 2009), quanto a sul, da confluência do rio Miranda à confluência do rio Nabileque (KUERTEN et al., 2013). $\mathrm{Na}$ área estudada, as três associações morfológicas descritas testemunham sucessivas mudanças hidrossedimentares, cuja identificação representa um passo importante no sentido da reconstituição da evolução geomorfológica da área desde o final do Pleistoceno. Como foi possível verificar que as três associações representam três eventos hidrossedimentares diferenciados e sucessivos, propõe-se um modelo evolutivo para a planície do Paraguai, sintetizado nos três cenários apresentados na figura 6 .

Os paleocanais com diques marginais, formadores 


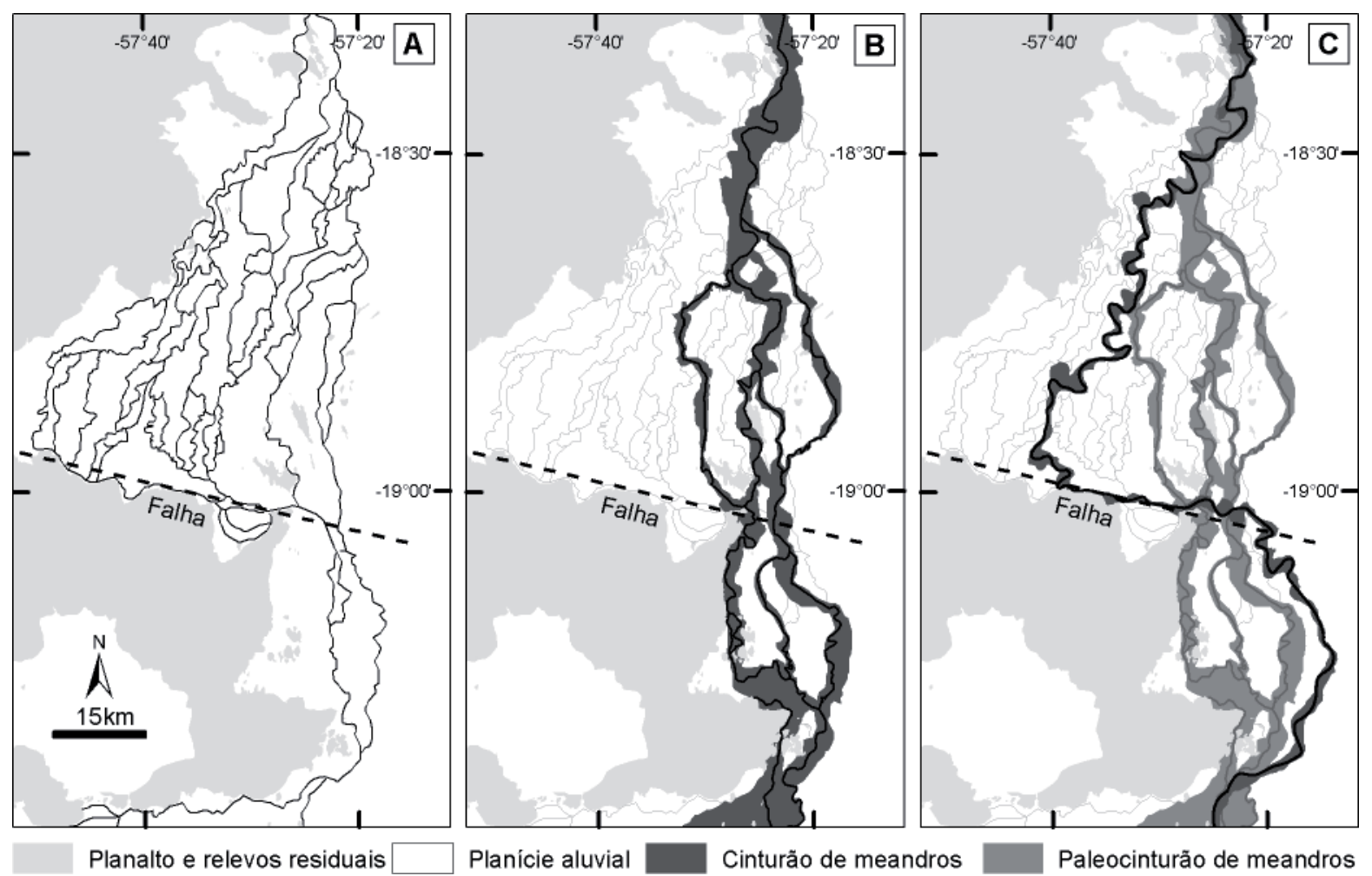

Figura 6 - Esquema evolutivo da planície do rio Paraguai: A) Do Pleistoceno tardio ao Holoceno inferior, a planície de inundação era caracterizada pela presença de paleorrede com padrão anabranching/distributário, formada por formas de canal-diques. B) No Holoceno inferior/médio formaram-se cinturões de meandros com orientação NS, truncando formas mais antigas; C) No Holoceno superior, após importante avulsão, o rio estabeleceu novo curso para SSW com desenvolvimento do cinturão de meandros atual, estabelecendo-se o rio Paraguai-Mirim como curso subajustado em paleocinturão de meandros.

da paleorrede de canais múltiplos são interpretados como as formas deposicionais mais antigas na planície de inundação (Figura 6-A). Os canais eram estreitos, com diques marginais desenvolvidos, e com frequentes bifurcações e reunificações. A planície alargava para sul, configurando paleorrede anabranching, localmente distributária. As águas eram coletadas a sul por canal controlado pela falha WNW que define a borda da bacia do Pantanal na área, colocando terrenos quaternários em contato direto com rochas do embasamento cristalino do planalto residual do Urucum (ASSINE; SOARES, 2004).

Não há datações disponíveis, mas considera-se que a formação dos paleocanais com padrão de drenagem anabranching/distributário ocorreu em intervalo do Pleistoceno tardio ao Holoceno inferior. Isto porque eles são cortados pelos paleocinturões de meandros, que são correlacionados ao paleocinturão do rio $\mathrm{Na}$ bileque situado a sul da área e datado como Holoceno inferior/médio por luminescência oticamente estimulada
(KUERTEN, 2010).

Dadas as características morfométricas dos canais, considera-se que tenham se formado em planície não-confinada sob regime de aumento na precipitação e na descarga fluvial. Aumento da umidade no intervalo de tempo situado do final do Pleistoceno ao Holoceno inferior e consequente aumento da descarga fluvial do rio Paraguai são corroborados por estudos realizados na lagoa Gaíva, situada a norte da área e geneticamente ligada à planície do rio Paraguai (WHITNEY et al., 2011; MCGLUE et al., 2012).

Mudanças similares foram reconhecidas a oeste, nas planícies orientais da Bolivia, onde May et al. (2008) destacaram a existência de paisagem produzida na transição Pleistoceno/Holoceno por aumento na descarga fluvial, na erosão dos solos e no aporte sedimentar. Na mesma linha, Latrubesse et al. (2012) interpretaram que a ausência de registros sedimentares do Holoceno inferior nos megaleques do Chaco Boliviano decorreu do aumento da descarga fluvial, erosão de antigos de- 


\section{Mudanças paleo-hidrológicas na planície do rio Paraguai, Quaternário do Pantanal}

pósitos e criação de vales incisos.

Os paleocinturões de meandros são interpretados como feições inicialmente erosivas, pois truncam depósitos mais antigos existentes na planície de inundação. Os cinturões foram formados por migração lateral de rios meandrantes, que se instalaram na planície em consequência de mudanças no regime hidrológico durante o Holoceno inferior/médio. Os canais tinham largura diminuída à medida que os cinturões se bifurcavam, não havendo evidências de truncamento entre eles, corroborando assim a hipótese de um sistema multicanal (anabranching) meandrante (Figura 6-B). A largura de alguns dos paleocanais encontrados no paleocinturão de meandros é menor que o do rio Paraguai atual (Figura 4), no entanto a diferença de largura pode não ter sido provocada por grandes variações na descarga fluvial, mas pelo fato do rio apresentar multicanais contemporâneos.

Segundo estudo de McGlue et al. (2012), o registro sedimentar da lagoa Gaíva revelou período mais seco no início e gradativamente mais úmido durante o Holoceno médio, responsável por inundações frequentes no Paraguai e expansão do lago entre 6,2 e 5,3 ka. Associado ao mesmo evento de expansão das áreas inundáveis, deu-se o estabelecimento de condições lacustres na baia do Castelo por volta de 6,5 ka (BEZERRA; MOZETTO, 2008). Com a subida do nível de base regional, as planícies foram palco de agradação fluvial, colmatando os cinturões que agora têm altimetria muito semelhante à planície na qual estão encaixados. A julgar pelas dimensões de alguns dos canais e meandros abandonados, formados ao final da agradação e ainda visíveis na superfície, o rio Paraguai tinha descarga fluvial semelhante à atual.

A agradação do paleocinturão de meandros, no trecho em que ele se apresenta com cerca de $4 \mathrm{~km}$ de largura, favoreceu a importante avulsão que mudou o curso do rio para a posição atual, ocorrida na latitude da baia do Castelo no limite entre o primeiro e o segundo trechos do curso atual (Figuras 3 e 4). Não há dados que permitam estabelecer com precisão quando ocorreu a avulsão, pois não se dispõe de datações dos sedimentos dos cinturões, mas, por analogia com fenômeno semelhante de avulsão do rio Paraguai na área do Nabileque, deve ter ocorrido no final do Holoceno médio. A avulsão na área do Nabileque ocorreu entre 6,5 e 3,9 ka (KUERTEN et al., 2013), tendo o rio Paraguai abandonado cinturão de meandros muito semelhante aos analisados neste trabalho, tanto em termos de largura quanto com relação à sua orientação NS.

Com o progressivo aumento da umidade no Holoceno superior, especialmente depois de 3,0 ka (WHITNEY et al., 2011; MCGLUE et al., 2012), o novo canal do rio Paraguai passou a entalhar os depósitos mais antigos. Desta forma, o rio Paraguai construiu um novo cinturão de meandros, que trunca, inclusive, os paleocinturões de meandros (Figura 6-C). E, à semelhança do rio Nabileque, o rio Paraguai-Mirim se instalou sobre um dos cinturões como um rio subajustado (underfit) em relação à planície em que corre, drenando as águas que inundam a planície durante as cheias e servindo de escoamento das águas do Taquari depois da avulsão Zé da Costa nos anos 1990.

\section{Conclusões}

Registros de mudanças paleo-hidrológicas marcam a paisagem da planície do rio Paraguai no trecho entre as confluências dos rios Cuiabá e Miranda. Análise de produtos de sensoriamento remoto e levantamentos de campo permitiram o reconhecimento e caracterização de associações morfológicas geneticamente distintas: 1) uma ampla área de planície de inundação com paleorrede de drenagem composta por paleocanais com diques marginais suavemente mais elevados que a planície; 2) paleocinturões de meandros que cortam a planície de norte para sul; 3 ) cinturão de meandros atual onde corre o rio Paraguai.

As diferentes associações morfológicas e suas relações genéticas testemunham sucessivas mudanças hidrológicas, cuja interpretação possibilitou a proposição de um modelo de evolução geomorfológica a partir do final do Pleistoceno. Do Pleistoceno tardio ao Holoceno inferior, a planície era caracterizada pela presença de rede de canais com diques marginais formando redes multicanais. A mudança do estilo fluvial, com implantação de cinturões de meandros de direção norte-sul, truncando as antigas formas deposicionais da planície, é atribuída ao aumento da umidade e da descarga fluvial no Holoceno inferior/médio. Agradação dos paleocinturões favoreceu a ocorrência de importante avulsão na transição Holoceno médio/superior, evento que mudou o curso do rio Paraguai e deu origem a um novo cinturão de meandros. 


\section{Agradecimentos}

Os autores agradecem à FAPESP (processo 2007/55987-3) e à FUNDECT/CNPq (processo 23/200.628/2012) pelo valioso apoio às nossas pesquisas no Pantanal; ao CNPq pela concessão da bolsa de mestrado ao primeiro autor (processo 131841/2011-4) e de bolsas de pesquisa aos segundo e sexto autores; e à UFMS-CPAN pelo apoio durante os trabalhos de campo.

\section{Referências}

AB'SÁBER, A. N. O Pantanal Mato-Grossense e a teoria dos refúgios. Revista Brasileira de Geografia, v.50, p.9-57, 1988.

ASSINE, M. L. Sedimentação na bacia do Pantanal MatoGrosssense, Centro-Oeste do Brasil. 105 f. Tese de LivreDocência - UNESP, Rio Claro-SP, 2003.

ASSINE, M. L. River avulsions on the Taquari megafan, Pantanal Wetland, Brazil. Geomorphology, v.70, p.357-371, 2005.

ASSINE, M. L. 2010. Pantanal Mato-Grossense: uma paisagem de exceção. In: Modenesi-Gauttieri, M. C.; Bartorelli, A.; Mantesso-Neto, V. Carneiro, C. D. R.; Lisboa, M. B. A. L. (eds.). A Obra de Aziz Nacib Ab’Saber. São Paulo, Beca-Ball Edições, p.464-489.

ASSINE, M. L.; SILVA, A. Contrasting fluvial styles of the Paraguay River in the northwestern border of the Pantanal wetland, Brazil. Geomorphology, v.113, p.189-199, 2009.

ASSINE, M. L.; SOARES, P. C. Quaternary of the Pantanal, west-central Brazil. Quaternary International, v.114, p.2324, 2004.

ASSINE, M. L.; PADOVANI, C.R., ZACHARIAS, A.A.; ANGULO, R.J.; SOUZA, M.C. Compartimentação geomorfológica, processo de avulsão fluvial e mudanças do curso do rio Taquari, Pantanal Mato-Grossense. Revista Brasileira de Geomorfologia, v.6, n.1, p.97-108, 2005.

ASSINE, M. L.; CORRADINI, F. A.; PUPIM, F. D. N.; MCGLUE, M. M. Channel arrangements and depositional styles in the São Lourenço fluvial megafan, Brazilian Pantanal wetland. Sedimentary Geology, v.301, p.172-184, 2014. DOI 10.1016/j. sedgeo.2013.11.007

BEZERRA, M. A. O.; MOZETO, A. A. Deposição de carbono orgânico na planície de inundação do rio Paraguai durante o Holoceno Médio. Oecologia Brasiliensis, v.12, n.1, p. 155171, 2008.

CARAGNANO, C. A. Late Pleistocene to recent climate change in Cordoba Province, Argentina. Quaternary International, v.57/58, p.117-134, 1999.

CRÓSTA, A. P. Processamento Digital de Imagens de Sensoriamento Remoto. Campinas: IG-UNICAMP, 1992.

GRIZIO, E. V.; SOUZA-FILHO, E. E.; ASSINE, M. L. Mobilidade do canal no rio Paraguai superior. Revista Brasileira de Geomorfologia, v.12, n.2, p.71-80, 2011.

JUNK, W. J.; BROWN, M.; CAMPBELL, I. C.; FINLAYSON, M.; GOPAL, B.; RAMBERG, L.; WARNER, B. G. The comparative biodiversity of seven globally important wetlands: a synthesis. Aquatic Sciences, v.68, p.400-414, 2006.

KNIGHTON, D. Fluvial forms and Process. New York: Ed. Arnold. 1984.

KUERTEN, S. Evolução geomorfológica e mudanças ambientais no megaleque do Nabileque, Quaternário do Pantanal Mato-Grossense. Tese de Doutorado (Geociências e Meio Ambiente) - UNESP, Rio Claro-SP, 2010.

KUERTEN S.; ASSINE, M.L. O rio Paraguai no megaleque do Nabileque, sudoeste do Pantanal Mato-Grossense, MS. Revista Brasileira de Geociências, v.41, n.4, p.655-666, 2011.

KUERTEN, S.; PAROLIN, M.; ASSINE, M. L.; MCGLUE, M. M. Sponge spicules indicate Holocene environmental changes on the Nabileque River floodplain, southern Pantanal, Brazil. Journal of Paleolimnology, v.49, p.171-183, 2013.

LATRUBESSE, E.M.; STEVAUX, J.C.; CREMON, E.H.; MAY, J.; TATUMI, S.H.; HURTADO, M.A.; BEZADA, M.; ARGOLLO, J.B. Late Quaternary megafans, fans and fluvio-aeolian interactions in the bolivian Chaco, Tropical South America. Palaeogeography, Palaeoclimatology, Palaeoecology, v.356-357, p.75-88, 2012.

LEOPOLD, B.L., WOLMAN, M.G., MILLER, J.P. Fluvial processes in geomorphology. Dover Publication, Inc, New York, 522p., 1964.

MAY, J. H.; ZECH, R.; VEIT, H. Late Quaternary paleosoilsediment-sequences and landscape evolution along the Andean piedmont, Bolivian Chaco. Geomorphology, v.98, p.34-54, 2008.

McGLUE, M.M.; SILVA, A.; ZANI, H.; CORRADINI, F.A.; PAROLIN, M.; ABEL, E.J.; COHEN, A.S.; ASSINE, M.L.; ELLIS, G.S.; TREES, M.A.; KUERTEN, S.; GRADELLA, F.S.; RASBOLD, G.G. Lacustrine records of Holocene flood pulse dynamics in the Upper Paraguay River watershed (Pantanal wetlands, Brazil). Quaternary Research, v.78, p.285-294, 2012. 
MIALL, A. D. The Geology of Fluvial Deposits. Berlin: Springer-Verlag, 1996.

SHUKLA, U. K. et al. A model of alluvial megafan sedimentation: Ganga Megafan. Sedimentary Geology, v.144, p.243-262, 2001.

SILVA, A. Geomorfologia do megaleque do rio Paraguai, Quaternário do Pantanal Mato-Grossense, Centro-Oeste do Brasil. Tese de Doutorado (Geociências e Meio Ambiente) - UNESP, Rio Claro-SP, 2010.

SILVA, A.; ASSINE, M. L.; ZANI, H.; SOUZA FILHO, E. E.; ARAÚJO, B. C. Compartimentação geomorfológica do rio Paraguai na borda norte do Pantanal Mato-Grossense, Região de Cáceres - MT. Revista Brasileira de Cartografia, v.59, p.73-81, 2007.

SILVA, A.; SOUZA FILHO, E. E. D.; CUNHA, S. B. D. Padrões de canal do rio Paraguai na região de Cáceres (MT). Revista Brasileira de Geociências, v. 38, n. 1, p. 167-177, 2008.

SMITH, L.M. Fluvial geomorphic features of the lower Mississipi alluvial valley. Engineering Geology, v.45, p.139165, 1996

SOARES, A. P., SOARES, P. C., ASSINE, M. L. Areiais e lagoas do Pantanal, Brasil: herança paleoclimática? Revista Brasileira de Geociências, v.33, n.2, p.211-224, 2003.

SOHN, M. F.; MAHAN, S. A.; KNOTT, J. R.; BOWMAN, D. D.
Luminescence ages for alluvial-fan deposits in Southern Death Valley: Implications for climate-driven sedimentation along a tectonically active mountain front. Quaternary International, v.166, p.49-60, 2007.

SOUZA, C. A. Dinâmica do corredor fluvial do rio Paraguai entre a cidade de Cáceres e a estação ecológica da ilha de Taiamã - MT. Tese de Doutorado - UFRJ, Rio de Janeiro-RJ, 2004.

STEVAUX, J.C. The upper Paraná River (Brazil): Geomorphology, sedimentology and paleoecology. Quaternary International, v.21, p.143-162, 1994

STEVAUX, J.C. Climatic events during the Late Pleistocene and Holocene in the Upper Parana River: Correlation with NE Argentina and South-Central Brazil. Quaternary International, v.72, p.73-86, 2000

TRICART, J. El Pantanal: un ejemplo del impacto geomorfologico sobre El ambiente. Informaciones Geograficas (Chile), v.29, p.81-97, 1982.

WHITNEY, B.S.; MAYLE, F.E.; PUNYASENA, S.W.; FITZPATRICK, K.A.; BURN, M.J.; GUILLEN, R.; CHAVEZ, E.; MANN, D.; PENNINGTON, R.T.; METCALFE, S.E. A 45 kyr palaeoclimate record from the lowland interior of tropical South America. Palaeogeography, Palaeoclimatology, Palaeoecology, v.307, p.177-192, 2011. 